\title{
The fragmentation pathways of azaspiracids elucidated using positive nanospray hybrid quadrupole time-of-flight (QqTOF) mass spectrometry
}

\author{
Brett Hamilton, Mónica Díaz Sierra, Mary Lehane, Ambrose Furey and Kevin J. James * \\ PROTEOBIO, Mass Spectrometry Centre for Proteomics and Biotoxin Research, Department of \\ Chemistry, Cork Institute of Technology, Cork, Ireland
}

\begin{abstract}
The azaspiracids, AZA1, AZA2 and AZA3, are the predominant shellfish toxins responsible for the human toxic syndrome, azaspiracid poisoning. Collision induced dissociation (CID) mass spectra were generated for azaspiracids using nano-electrospray ionisation (ESI) with a hybrid quadrupole time-of-flight (QqTOF) mass spectrometer in positive mode. Six main backbone fragmentations of the polyether skeleton of azaspiracids were observed as well as multiple neutral losses of water molecules from the parent and product ions. The characteristic charge-remote fragmentation of the carbon skeleton of azaspiracids produced nitrogenous ions. The three azaspiracids differ from one another by $14 \mathrm{Da}$ due to methylation in the A- and E-rings. Three fragmentation pathways, involving cleavage of the E-ring, C27-C28 and G-ring, gave ions that were common to all azaspiracids. Another three fragmentations involving the A-ring, C-ring and C19-C20, were useful for distinguishing between azaspiracid analogues. Multiple tandem ion-trap mass spectrometry $\left(\mathrm{MS}^{n}\right)$ was used to confirm the fragmentation pathways.
\end{abstract}

\section{Introduction}

Azaspiracids are a group of toxins, produced by marine phytoplankton, which causes azaspiracid poisoning (AZP) [1,2]. This human illness is characterised by a severe gastrointestinal disturbance following the ingestion of bivalve shellfish that accumulate azaspiracids [1]. Azaspiracids are potent toxins that can induce pathological changes to the liver, pancreas, thymus and spleen and chronic exposure may induce tumours [3]. Like most marine polyether toxins, azaspiracids originate in microalgae and it has recently been shown that azaspiracids have contaminated shellfish throughout Europe [4,5]. The special structural features of azaspiracids (Fig. 1) include a 6,5,6-trispiroacetal ring construction (rings $\mathrm{A}, \mathrm{B}$, and $\mathrm{C}$ ) and a 2,9-dioxabicyclo[3.3.1]nonane ring fused with an azaspiro ring (rings F, G, H, and I) [1]. The most abundant azaspiracids in shellfish, AZA1, AZA2 and AZA3, differ from one another by methylation at C-8 on the A-ring and C-22 on the E-ring [2,6]. A number of other azaspiracids that are minor contaminants in shellfish, have been identified. These include AZA6, an isomer of AZA1, and seven 3- and 23-hydroxy analogues [7]. The unusual structural features of azaspiracids has prompted a number of synthetic attempts which have led to a revision in the structure of AZA1 from that originally published $[8,9]$.

\footnotetext{
*Corresponding author. Tel.: +353 21 4326317; Fax: +353 21 4345191; E-mail: kjames@cit.ie.
} 


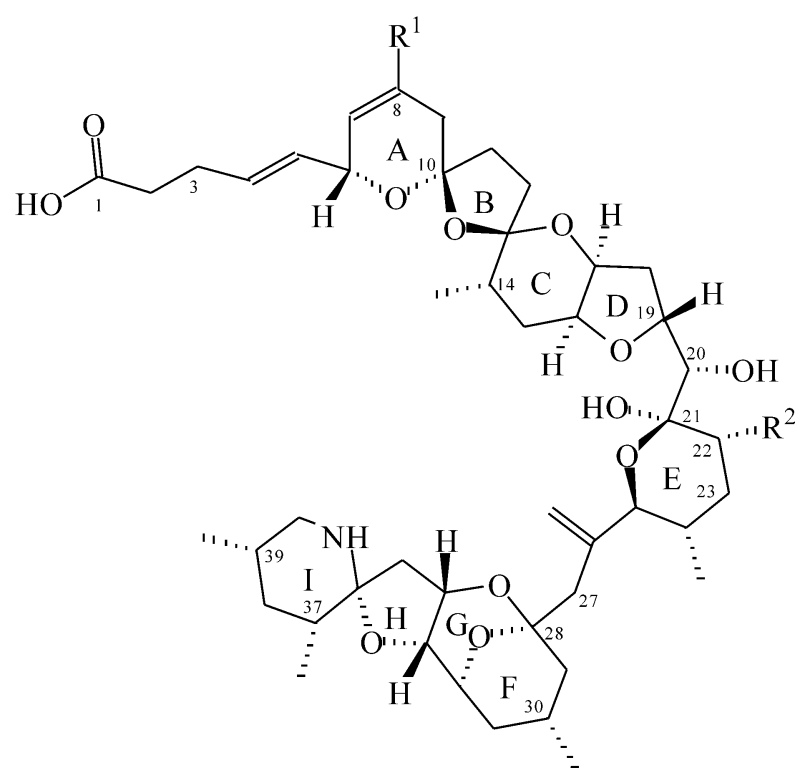

Fig. 1. Azaspiracid-1 (AZA1), $\mathrm{R}^{1}=\mathrm{H}, \mathrm{R}^{2}=\mathrm{CH}_{3}$; azaspiracid-2 (AZA2), $\mathrm{R}^{1}=\mathrm{R}^{2}=\mathrm{CH}_{3}$; azaspiracid-3 (AZA3), $\mathrm{R}^{1}=\mathrm{R}^{2}=\mathrm{H}$.

In the past fifty years, mass spectrometry has been an important tool in the structural elucidation of naturally occurring compounds that ranged from alkaloids to proteins $[10,11]$. The mass spectra of polyether compounds frequently show product ion signals due to the successive loss of water molecules [12, 13]. A number of sensitive analytical methods for the determination of azaspiracids have been developed using liquid chromatography, coupled via an electrospray ion source, to a triple quadrupole or a quadrupole ion-trap mass spectrometer [14-18]. This study of the fragmentation processes of azaspiracids, in positive mode, utilised hybrid quadrupole time-of-flight mass spectrometry (QqTOF-MS) and an iontrap instrument for multiple tandem experiments $\left(\mathrm{MS}^{n}\right)$ to reveal the characteristic pathways. The lack of availability of reference standard marine toxins has inhibited studies on these complex molecules [13] and a previous report that relied on the use of liquid chromatography to separate toxins in crude extracts of shellfish tissues failed to generate satisfactory $\mathrm{MS}^{n}$ data [18]. Nano ESI sources are ideal for MS studies when sample is very scarce and as little as $10 \mathrm{pg}$ of standard is sufficient to perform over one hour of QqTOF-MS experiments [19]. This mass spectrometric method has now been applied to study the main fragmentation pathways of the three predominant azaspiracids which will aid the structural elucidation of new minor analogues and biotransformation products.

\section{Instrumentation}

\subsection{Nanospray hybrid quadrupole time-of-flight (QqTOF) mass spectrometry}

A quadrupole/time-of-flight mass spectrometer (Qstar, Applied Biosystems, Foster City, CA, USA) with a nanospray (ES023C, Protana, Denmark) ionsource was used to produce collision ionisation dissociation (CID) spectra in positive mode. Azaspiracid standards (AZA1, AZA2 and AZA3) were dissolved in methanol $(0.01 \mu \mathrm{g} / 10 \mu \mathrm{l})$. CID spectra were obtained from the $[\mathrm{M}+\mathrm{H}]^{+}$ions of each toxin; $m / z 842$ (AZA1), 856 (AZA2) and 828 (AZA3). The solution to be analysed (5-10 $\mu \mathrm{l}$ ) was loaded 
into a nanospray capillary (Long NanoES spray capillary, ES381, Protana, Denmark) using a 0.5-10 $\mu$ 1 eppendorf GELoader tip and a TOMY PMC-060 Capsulefuge. Once opened, an ionsource voltage (IS) of $-1000 \mathrm{~V}$ was applied to the tip of the nanospray capillary to generate a spray. While scanning in the range, $m / z 50-1000$, the voltages used were: declustering potential (DP) $=45 \mathrm{~V}$, focusing potential $(\mathrm{FP})=205 \mathrm{~V}$, declustering potential-2 $(\mathrm{DP} 2)=15 \mathrm{~V}$, collision gas $(\mathrm{CAD})=4$. The values for ion release delay (IRD) and ion release width (IRW) are directly related to the mass range being scanned when using the 'enhance all ions' function. Collision energies of $40-60 \mathrm{~V}$ were used during acquisitions.

\subsection{Liquid chromatography-quadrupole ion-trap mass spectrometry}

The liquid chromatography system was a Waters 2690 Alliance (Waters Corporation, Milford, MA, USA). The analytical column was a Luna-2 C-18 $(5 \mu \mathrm{m}, 150 \times 2.0 \mathrm{~mm}$, Phenomenex, Macclesfield, UK) which was maintained at $35^{\circ} \mathrm{C}$. Isocratic chromatography was carried out using acetonitrile-water (60/40) containing $0.05 \%$ trifluoroacetic acid TFA and $0.5 \mathrm{mM}$ ammonium acetate at a flow rate of $200 \mu \mathrm{l} / \mathrm{min}$. Mass spectral analyses were performed using an LCQ ion-trap mass spectrometer (ThermoFinnigan, San Jose, CA, USA). MS experiments were carried out using electrospray ionisation (ESI) in positive mode, as detailed previously [16]. The ESI needle voltage was $4 \mathrm{kV}$, producing a spray current of approximately $80 \mu \mathrm{A}$. The capillary voltage was $10 \mathrm{~V}$ and the heated capillary temperature was $200^{\circ} \mathrm{C}$. Full chromatographic and LCQ operation parameters have been previously described $[16,17]$.

\section{Results and discussion}

It has previously been shown that the collision induced dissociation (CID) mass spectra of azaspiracids, using positive ESI, display neutral loss ions due to the elimination of up to five water molecules. CID mass spectra were generated for azaspiracids using nano-electrospray ionisation (ESI) with a hybrid quadrupole time-of-flight (QqTOF) mass spectrometer in positive mode. A series of backbone cleavages were observed that ranged from the A-ring down to the G-ring (Fig. 1). These characteristic charge-remote fragmentations of the carbon skeleton of azaspiracids produced ions that contain nitrogen. The positive CID MS of other polyether toxins, such as okadaic acid, are complex due to charge mobility. Although migration of charge to oxygen atoms in the A-E ring system of azaspiracids is possible, this was not significant as there was no evidence of fragment ions that do not contain nitrogen. The strong tendency for charge to remain on the nitrogen of azaspiracids during fragmentation leads to ion series that are readily interpretable. Six characteristic backbone fragmentations of the polyether skeleton of azaspiracids were observed, as well as neutral losses of water molecules from the parent and product ions (Fig. 1). The three azaspiracids differ from one another by $14 \mathrm{Da}$ due to methylation at $\mathrm{C} 8$ of the A-ring and $\mathrm{C} 22$ of the E-ring. The other known azaspiracids are mainly hydroxylated analogues with substituents at $\mathrm{C} 3$ or $\mathrm{C} 23$.

Products ions emanating from the C-ring and C19-C20 cleavages were only observed along with water-losses. The A-ring, C-ring and C19-C20 cleavages result in the loss of fragments containing $\mathrm{R}^{1}$, leaving product ions that retain $\mathrm{R}^{2}$. Therefore, these ions in the AZA2 spectrum differ from AZA1 by an additional $14 \mathrm{Da}$ since $\mathrm{R}^{2}$ is a methyl moiety in AZA2. The corresponding ions from AZA3 differ by 14 Da less than AZA1 (Fig. 2). Since all of the known azaspiracid structural variants involve substituents located at or between C3 and C23, the E-ring, C27-C28 and H-ring cleavages produced nitrogenous ions that are equivalent in all known azaspiracids. The ions produced are at $m / z 362,280$ and 168 respectively, together with water-loss ions. 


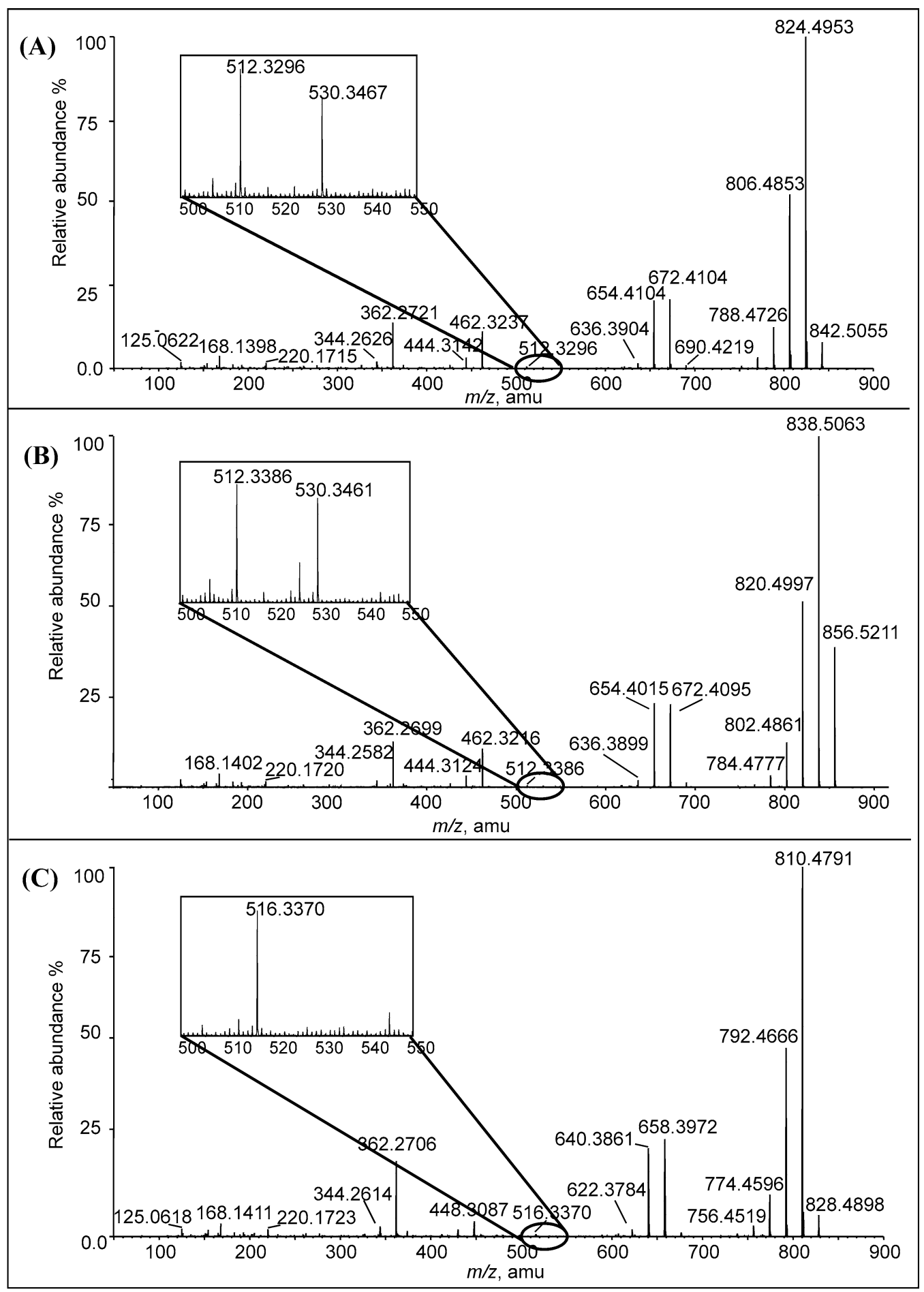

Fig. 2. Positive ESI spectra of (A) AZA1, (B) AZA2 and (C) AZA3, obtained using a nanospray source on a hybrid quadrupole time-of-flight (QqTOF) mass spectrometer. 


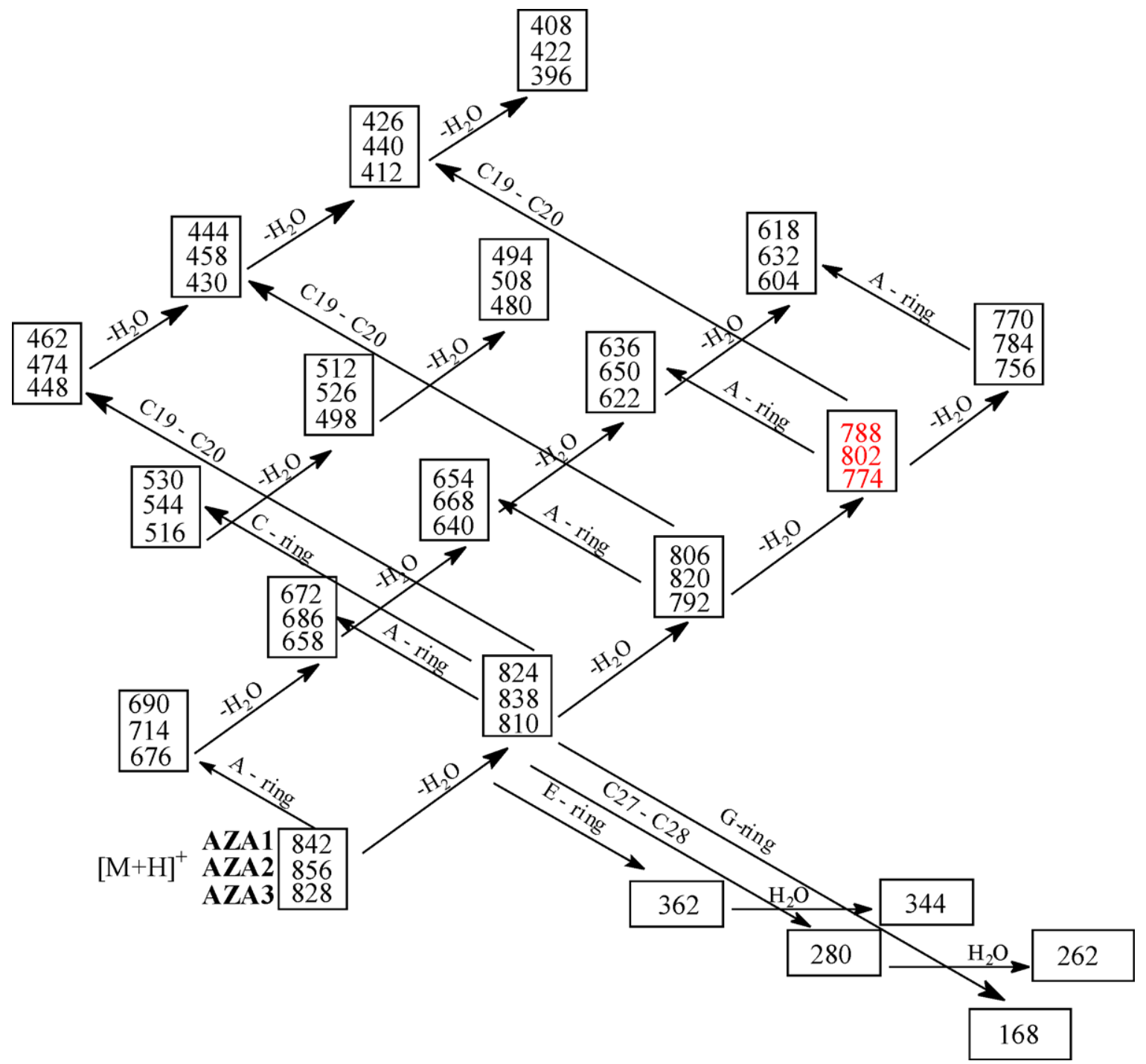

Fig. 3. The main product ions of AZA1-AZA3 and the six main fragmentation pathways generated using QqTOF and LCQ ion-trap mass spectrometers, acquired in positive ion mode.

Three fragmentations, involving the A-ring, C-ring and C19-C20, were important in generating ions that could be used to distinguish between azaspiracid analogues. The ion series, $m / z 690-618$ (Fig. 3) is due to the fracture of the A-ring with multiple water losses, $\left[\mathrm{M}+\mathrm{H}-n \mathrm{H}_{2} \mathrm{O}-\mathrm{C}_{9} \mathrm{H}_{11} \mathrm{O}_{2} \mathrm{R}^{1}\right]^{+}$. The ion series, $m / z$ 530-494, due to fragmentation at the C-ring, and the series $m / z 462-408$, due to C19C20 fragmentation, included water losses. It is apparent that these nitrogenous ions were generated by charge-remote fragmentation processes with the charge on the GHI ring system. Whilst high mass accuracy data (Table 1), generated by the QqTOF-MS, was used to propose the formulae of fragment ions, the fragmentation pathways were delineated by ion-trap $\operatorname{MS}^{n}(n=2-5)$ experiments (Fig. 3). The low mass cut-off value in quadrupole ion trap MS (ThermoFinnigan LCQ) is approximately one third of the parent mass and this precludes the observation of the $m / z 168$ (G-ring fragment ion). The theoretical 
Table 1

High accuracy mass data for AZA1-AZA3 produced by positive nano ESI QqTOF-MS

\begin{tabular}{|c|c|c|c|c|c|}
\hline \multicolumn{2}{|c|}{ AZA1 } & \multicolumn{2}{|c|}{ AZA2 } & \multicolumn{2}{|c|}{ AZA3 } \\
\hline $\begin{array}{l}\text { Product ion } \\
\text { formulae }\end{array}$ & $\begin{array}{l}\text { Found } \\
(\mathrm{ppm})^{*}\end{array}$ & $\begin{array}{l}\text { Product ion } \\
\text { formulae }\end{array}$ & $\begin{array}{l}\text { Found } \\
(\mathrm{ppm})^{*}\end{array}$ & $\begin{array}{l}\text { Product ion } \\
\text { formulae }\end{array}$ & $\begin{array}{l}\text { Found } \\
(\mathrm{ppm})^{*}\end{array}$ \\
\hline$\overline{\mathrm{C}_{47} \mathrm{H}_{70} \mathrm{NO}_{11}}$ & $\begin{array}{c}824.4953 \\
(0)\end{array}$ & $\mathrm{C}_{48} \mathrm{H}_{72} \mathrm{NO}_{11}$ & $\begin{array}{c}838.5063 \\
(5)\end{array}$ & $\mathrm{C}_{46} \mathrm{H}_{68} \mathrm{NO}_{11}$ & $\begin{array}{c}810.4791 \\
\text { (0) }\end{array}$ \\
\hline $\mathrm{C}_{47} \mathrm{H}_{68} \mathrm{NO}_{10}$ & $\begin{array}{c}806.4853 \\
\text { (1) }\end{array}$ & $\mathrm{C}_{48} \mathrm{H}_{70} \mathrm{NO}_{10}$ & $\begin{array}{c}820.4997 \\
(0.4)\end{array}$ & $\mathrm{C}_{46} \mathrm{H}_{66} \mathrm{NO}_{10}$ & $\begin{array}{c}792.4666 \\
\text { (3) }\end{array}$ \\
\hline $\mathrm{C}_{38} \mathrm{H}_{60} \mathrm{NO}_{10}$ & $\begin{array}{c}690.4219 \\
(0.2)\end{array}$ & $\mathrm{C}_{38} \mathrm{H}_{60} \mathrm{NO}_{10}$ & $\begin{array}{c}690.4210 \\
\text { (1) }\end{array}$ & $\mathrm{C}_{37} \mathrm{H}_{58} \mathrm{NO}_{10}$ & $\begin{array}{c}676.4069 \\
\text { (1) }\end{array}$ \\
\hline $\mathrm{C}_{38} \mathrm{H}_{58} \mathrm{NO}_{9}$ & $\begin{array}{c}672.4104 \\
\text { (1) }\end{array}$ & $\mathrm{C}_{38} \mathrm{H}_{58} \mathrm{NO}_{9}$ & $\begin{array}{c}672.4095 \\
\text { (3) }\end{array}$ & $\mathrm{C}_{37} \mathrm{H}_{56} \mathrm{NO}_{9}$ & $\begin{array}{c}658.3972 \\
\text { (3) }\end{array}$ \\
\hline $\mathrm{C}_{38} \mathrm{H}_{56} \mathrm{NO}_{8}$ & $\begin{array}{c}654.4024 \\
\text { (3) }\end{array}$ & $\mathrm{C}_{38} \mathrm{H}_{56} \mathrm{NO}_{8}$ & $\begin{array}{c}654.4015 \\
\text { (1) }\end{array}$ & $\mathrm{C}_{37} \mathrm{H}_{54} \mathrm{NO}_{8}$ & $\begin{array}{c}640.3861 \\
\text { (2) }\end{array}$ \\
\hline $\mathrm{C}_{31} \mathrm{H}_{48} \mathrm{NO}_{6}$ & $\begin{array}{c}530.3467 \\
\text { (3) }\end{array}$ & $\mathrm{C}_{31} \mathrm{H}_{48} \mathrm{NO}_{6}$ & $\begin{array}{c}530.3461 \\
\text { (4) }\end{array}$ & $\mathrm{C}_{30} \mathrm{H}_{46} \mathrm{NO}_{6}$ & $\begin{array}{c}516.3370 \\
(9)\end{array}$ \\
\hline $\mathrm{C}_{31} \mathrm{H}_{46} \mathrm{NO}_{5}$ & $\begin{array}{c}512.3296 \\
(16)\end{array}$ & $\mathrm{C}_{31} \mathrm{H}_{46} \mathrm{NO}_{5}$ & $\begin{array}{c}512.3386 \\
\text { (2) }\end{array}$ & $\mathrm{C}_{30} \mathrm{H}_{44} \mathrm{NO}_{5}$ & $\begin{array}{c}498.3235 \\
(12)\end{array}$ \\
\hline $\mathrm{C}_{27} \mathrm{H}_{44} \mathrm{NO}_{5}$ & $\begin{array}{c}462.3237 \\
\text { (4) }\end{array}$ & $\mathrm{C}_{27} \mathrm{H}_{44} \mathrm{NO}_{5}$ & $\begin{array}{c}462.3216 \\
(0.6)\end{array}$ & $\mathrm{C}_{26} \mathrm{H}_{42} \mathrm{NO}_{5}$ & $\begin{array}{c}448.3087 \\
\text { (5) }\end{array}$ \\
\hline $\mathrm{C}_{27} \mathrm{H}_{42} \mathrm{NO}_{4}$ & $\begin{array}{c}444.3142 \\
(6)\end{array}$ & $\mathrm{C}_{27} \mathrm{H}_{42} \mathrm{NO}_{4}$ & $\begin{array}{c}444.3124 \\
\text { (2) }\end{array}$ & $\mathrm{C}_{26} \mathrm{H}_{40} \mathrm{NO}_{4}$ & $\begin{array}{c}430.2982 \\
(6)\end{array}$ \\
\hline $\mathrm{C}_{22} \mathrm{H}_{36} \mathrm{NO}_{3}$ & $\begin{array}{c}362.2721 \\
\text { (7) }\end{array}$ & $\mathrm{C}_{22} \mathrm{H}_{36} \mathrm{NO}_{3}$ & $\begin{array}{c}362.2699 \\
\text { (1) }\end{array}$ & $\mathrm{C}_{22} \mathrm{H}_{36} \mathrm{NO}_{3}$ & $\begin{array}{c}362.2706 \\
\text { (3) }\end{array}$ \\
\hline $\mathrm{C}_{22} \mathrm{H}_{34} \mathrm{NO}_{2}$ & $\begin{array}{c}344.2626 \\
(10)\end{array}$ & $\mathrm{C}_{22} \mathrm{H}_{34} \mathrm{NO}_{2}$ & $\begin{array}{c}344.2582 \\
\text { (2) }\end{array}$ & $\mathrm{C}_{22} \mathrm{H}_{34} \mathrm{NO}_{2}$ & $\begin{array}{c}344.2614 \\
\text { (7) }\end{array}$ \\
\hline $\mathrm{C}_{16} \mathrm{H}_{24} \mathrm{NO}_{2}$ & $\begin{array}{c}262.1816 \\
\text { (3) }\end{array}$ & $\mathrm{C}_{16} \mathrm{H}_{24} \mathrm{NO}_{2}$ & $\begin{array}{c}262.1839 \\
(12)\end{array}$ & $\mathrm{C}_{16} \mathrm{H}_{24} \mathrm{NO}_{2}$ & $\begin{array}{c}262.1824 \\
\text { (6) }\end{array}$ \\
\hline $\mathrm{C}_{10} \mathrm{H}_{18} \mathrm{NO}$ & $\begin{array}{c}168.1398 \\
(6)\end{array}$ & $\mathrm{C}_{10} \mathrm{H}_{18} \mathrm{NO}$ & $\begin{array}{c}168.1402 \\
(8)\end{array}$ & $\mathrm{C}_{10} \mathrm{H}_{18} \mathrm{NO}$ & $\begin{array}{c}168.1411 \\
(14)\end{array}$ \\
\hline
\end{tabular}

*Error values in parenthesis refer to differences between theoretical and found masses in part per million (ppm).

accurate mass values of the $[\mathrm{M}+\mathrm{H}]^{+}$ions of AZA1-AZA3 were used for the final mass calibration. The main product ion masses that were found were in good agreement with calculated masses corresponding to the formulae of the proposed fragment structures (Table 1). All of the mass error values were within $16 \mathrm{ppm}$ of the calculated masses and most were significantly less than this value (Table 1).

\section{Fragmentation of deuterated azaspiracids}

The mass spectra of marine toxins containing fused polyether rings often display signals due to multiple water losses that are regarded as non-informative for structural elucidation [13,20,21]. However, azaspiracids contain a vicinal diol moiety which would be expected to lose water more readily than an ether ring. To obtain evidence in support of this, ion-trap $\mathrm{MS}^{n}$ experiments were also performed following $\mathrm{H} / \mathrm{D}$ exchange. AZA1 was dissolved in methanol- $\mathrm{d}_{4}$ and the liquid chromatography mobile phase was $\mathrm{D}_{2} \mathrm{O}$ /acetonitrile. $\mathrm{H} / \mathrm{D}$ exchange has been widely used to study the structures of drugs and their metabolites [22,23]. AZA1 contains several groups with exchangeable hydrogen atoms, including 


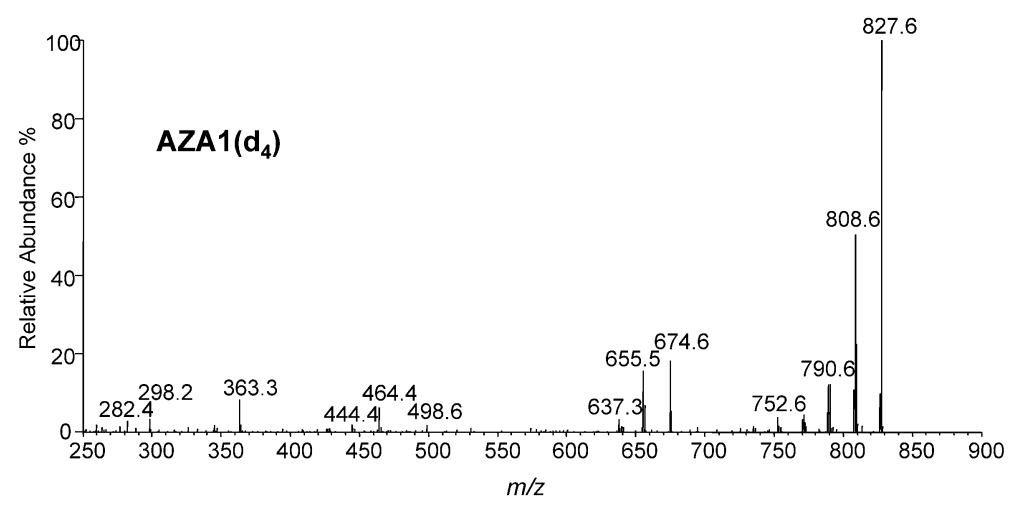

Fig. 4. Positive ESI MS ${ }^{2}$ spectrum of AZA1, following H/D exchange. Product ion spectrum of the fully exchanged $\left[\mathrm{M}\left(\mathrm{d}_{4}\right)+\mathrm{D}\right]^{+}$ions, $m / z 846$, AZA1 $\left(\mathrm{d}_{4}\right)$, was obtained using an LCQ quadrupole ion-trap mass spectrometer.

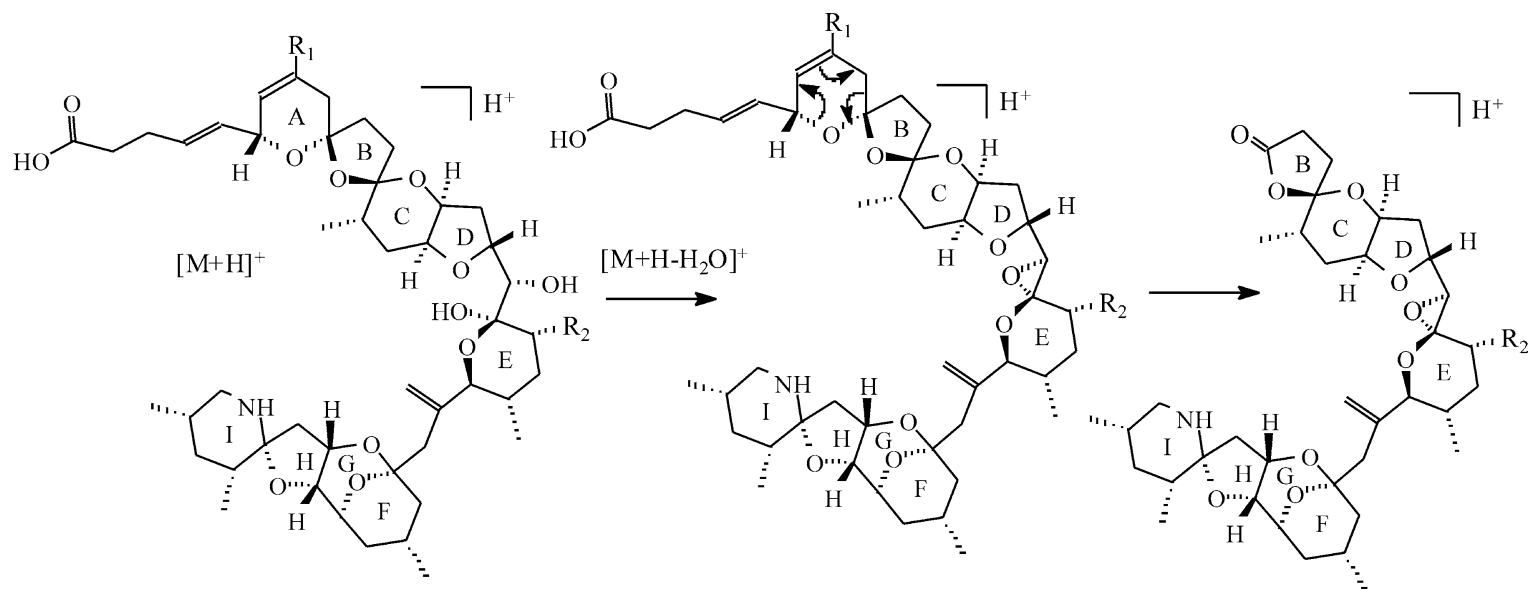

Fig. 5. Proposed water-loss structures and A-ring fragmentation mechanism of azaspiracids.

the amine, carboxylic acid and diol moieties. The molecular-related ion in the full-scan spectrum was $m / z=847$, which is a difference of $5 \mathrm{Da}$ from the protonated ion. This mass difference is as a result of H/D exchange involving the carboxylic acid, the diol at C20 and C21, and the amine moiety plus deuteration of the latter. The $\mathrm{MS}^{2}$ spectrum, using a relative collision energy (RCE) of $80 \%$, showed that the first water loss in the non-deuterated experiments became a $20 \mathrm{Da}$ loss in the deuterated experiments (Fig. 4). This demonstrates that the water-loss processes in azaspiracids, previously regarded as non-informative [21], are clearly not equivalent. The $20 \mathrm{Da}$ loss can be explained if epoxide formation from the $\mathrm{C} 20-\mathrm{C} 21$ diol is the dominant initial fragmentation process. Proposed structures for the first water-loss ion and the mechanism for the subsequent A-ring fragmentation are shown in Fig. 5.

\section{Conclusions}

The first water-loss ion in the spectra of azaspiracids resulted from dehydration at the vicinal diol at C20-C21. Six main MS pathways of azaspiracids involving fragmentation of the carbon skeleton resulted from cleavages remote to the nitrogen, starting at C9-C10 on the A-ring down to the G-ring. The 
A-ring fragmentation was the most facile fragmentation involving the carbon skeleton of azaspiracids. Three backbone fragmentation processes produced ions that were equivalent in all of the known azaspiracid analogues. A further three fragmentation processes, involving the A-ring, C-ring and C19-C20, revealed structural differences between azaspiracids.

\section{Acknowledgements}

We acknowledge funding from the EU sponsored programmes, Higher Education Authority of Ireland, PRTLI-2, Irish Research Council for Science, Engineering and Technology (IRCSET) post-doctoral fellowship (to M.L.), under the National Development Plan, and a post-doctoral fellowship (to M.D.S) from FICYT, Spain.

\section{References}

[1] M. Satake, K. Ofuji, H. Naoki, K.J. James, A. Furey, T. McMahon, J. Silke and T. Yasumoto, J. Am. Chem. Soc. 120 (1998), 9967.

[2] K. Ofuji, M. Satake, T. McMahon, J. Silke, K.J. James, H. Naoki, Y. Oshima and T. Yasumoto, Natural Toxins 7 (1999), 99.

[3] E. Ito, M. Satake, K. Ofuji, N. Kurita, T. McMahon, K.J. James and T. Yasumoto, Toxicon 38 (2000), 917.

[4] K.J. James, C. Moroney, C. Roden, M. Satake, T. Yasumoto, M. Lehane and A. Furey, Toxicon 41 (2003), 145.

[5] K.J. James, A. Furey, M. Lehane, H. Ramstad, T. Aune, P. Hovgaard, S. Morris, W. Higman, M. Satake and T. Yasumoto, Toxicon 40 (2002), 909.

[6] K. Ofuji, M. Satake, T. McMahon, K.J. James, H. Naoki, Y. Oshima and T. Yasumoto, Biosci. Biotechnol. Biochem. 65 (2001), 740.

[7] K.J. James, M. Diaz Sierra, A. Furey, M. Lehane and A. Braña Magdalena, Toxicon 41 (2003), 277.

[8] K.C. Nicolaou, Y.W. Li, N. Uesaka, T.V. Koftis, S. Vyskocil, T.T. Ling, M. Govindasamy, W. Qian, F. Bernal and D.Y.K. Chen, Angew. Chem. Int. Ed. 42 (2003), 3643.

[9] K.C. Nicolaou, D.Y.K. Chen, Y.W. Li, W.Y. Qian, T.T. Ling, S. Vyskocil, T.V. Koftis, M. Govindasamy and N. Uesaka, Angew. Chem. Int. Ed. 42 (2003), 3649.

[10] J.S. Grossert, Int. J. Mass Spectrom. 212 (2001), 65.

[11] K. Biemann, J. Am. Soc. Mass Spectrom. 13 (2002), 1254.

[12] M.A. Quilliam, in: Applications of LC-MS in Environmental Chemistry, D. Barcelo, ed., Vol. 59, Elsevier, Amsterdam, 1996, p. 415.

[13] R.J. Lewis, M.J. Holmes, P.F. Alewood and A. Jones, Natural Toxins 2 (1994), 56.

[14] R. Draisci, L. Palleschi, E. Ferretti, A. Furey, K.J. James, M. Satake and T. Yasumoto, J. Chromatogr. 871 (2000), 13.

[15] K.J. James, A. Furey, M. Lehane, C. Moroney, M. Satake and T. Yasumoto, in: Mycotoxins and Phycotoxins in Perspective at the Turn of the Century, W.J. deKeo, R.A. Samson, H.P. van Egmond, J. Gilbert and M. Sabino, eds, W.J. deKeo, Wageningen, 2001, p. 401

[16] A. Furey, A. Braña Magdalena, M. Lehane, C. Moroney, K.J. James, M. Satake and T. Yasumoto, Rapid Commun. Mass. Spectrom. 16 (2002), 238.

[17] M. Lehane, A. Braña Magdalena, C. Moroney, A. Furey and K.J. James, J. Chromatogr. 950 (2002), 139.

[18] D.A. Volmer, S. Brombacher and B. Whitehead, Rapid Commun. Mass Spectrom. 16 (2002), 2298.

[19] M. Poutanen, L. Salusjarvi, L. Ruohonen, M. Penttila and N. Kalkkinen, Rapid Commun. Mass Spectrom. 15 (2001), 1685.

[20] R. Draisci, L. Lucentini, L. Giannetti, P. Boria, K.J. James, A. Furey, M. Gillman and S.S. Kelly, J. AOAC. Int. 81 (1998), 441.

[21] S. Brombacher, S. Edmonds and D.A. Volmer, Rapid Commun. Mass Spectrom. 16 (2002), 2306.

[22] W. Lam and R. Ramanathan, J. Am. Soc. Mass Spectrom. 13 (2002), 345.

[23] A.M. Kamel, H.G. Fouda, P.R. Brown and B. Munson, J. Am. Soc. Mass Spectrom. 13 (2002), 543. 


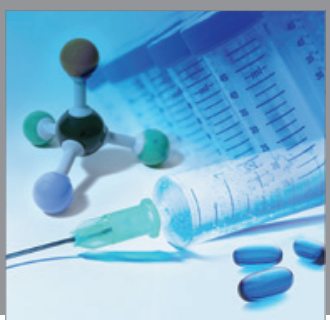

International Journal of

Medicinal Chemistry

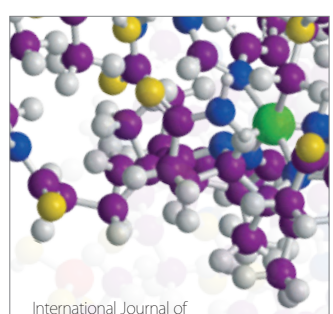

Carbohydrate Chemistry

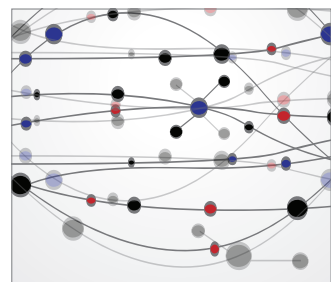

The Scientific World Journal
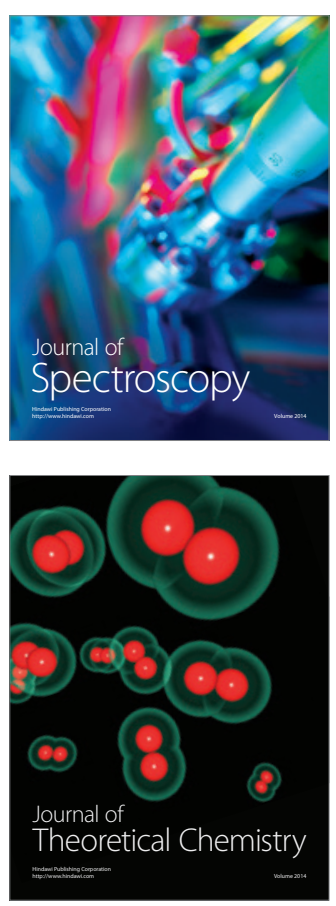
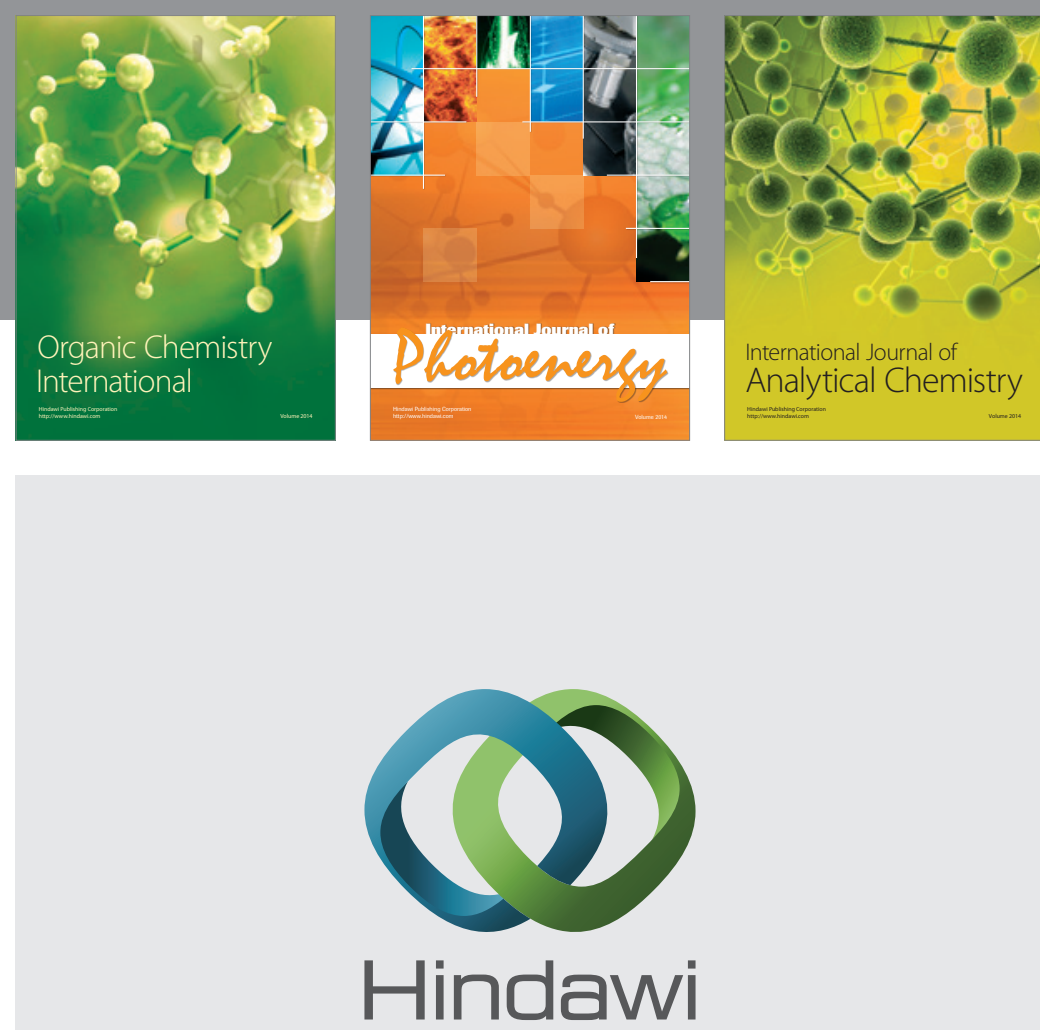

Submit your manuscripts at

http://www.hindawi.com
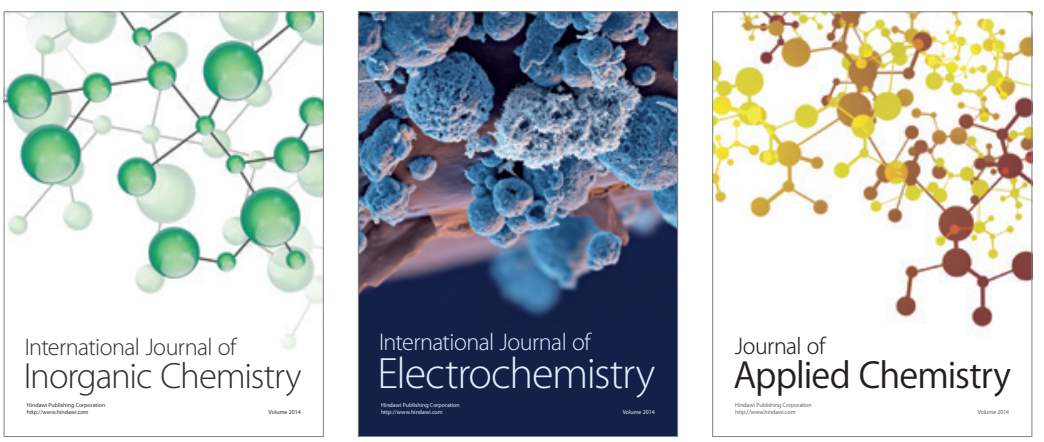

Journal of

Applied Chemistry
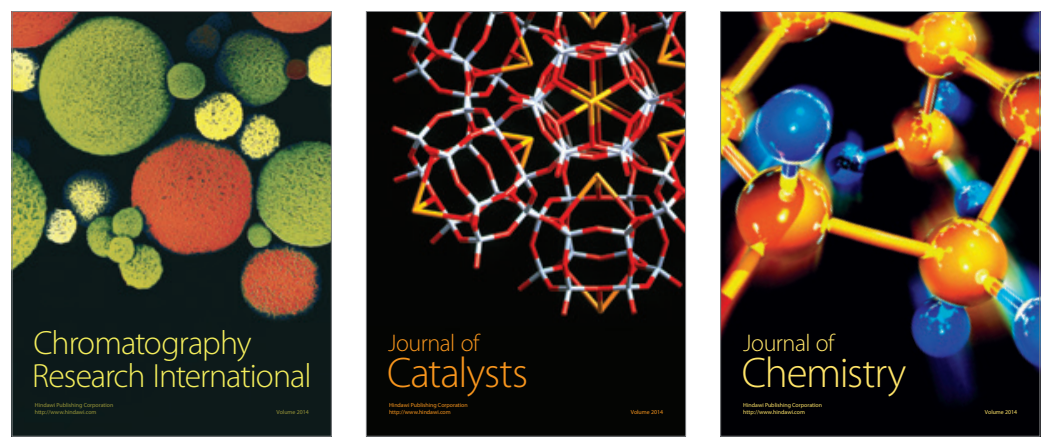
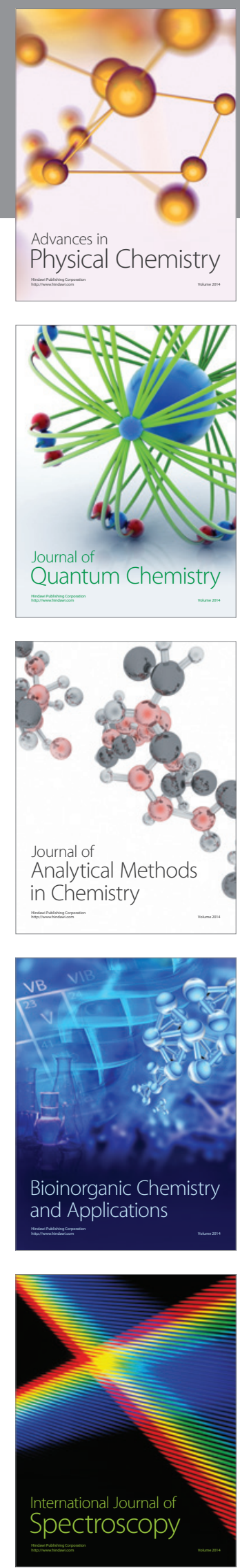